\title{
Entrar na idade mídia, sem perder a identidade regional
}

\author{
José Marques de Melo
}

\section{SciELO Books / SciELO Livros / SciELO Libros}

MELO, JM. Cidadania glocal, identidade nordestina: ética da comunicação na era da internet [online]. Campina Grande: EDUEPB; Latus, 2011. 108 p. ISBN 978-85-63984-07-4. Available from SciELO Books $<\underline{\text { http: } / / \text { books.scielo.org }>\text {. }}$

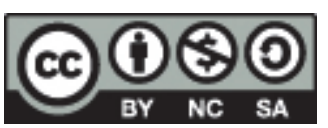

All the contents of this work, except where otherwise noted, is licensed under a Creative Commons Attribution-Non Commercial-ShareAlike 3.0 Unported.

Todo o conteúdo deste trabalho, exceto quando houver ressalva, é publicado sob a licença Creative Commons Atribuição Uso Não Comercial - Partilha nos Mesmos Termos 3.0 Não adaptada.

Todo el contenido de esta obra, excepto donde se indique lo contrario, está bajo licencia de la licencia Creative Commons Reconocimento-NoComercial-CompartirIgual 3.0 Unported. 


\section{Entrar na idade mídia, sem perder a identidade regional ${ }^{2}$}

Nenhuma metáfora simboliza melhor o nosso país do que a expressão tão cara aos intelectuais emblemáticos que foram Darcy Ribeiro, Gilberto Freyre e Manuel Diegues Júnior. Eles se referem ao Brasil como um arquipélago cultural, cuja constituição geofísica assemelha-se a um conjunto de ilhas. Sua unidade geopolítica foi historicamente preservada por três instituições hegemônicas: a língua portuguesa, a religião católica e o sistema federativo que preside o nosso governo, da monarquia à república.

2 Discurso escrito para ser lido no dia 15 de setembro de 2010, na Assembléia Legislativa de Pernambuco, na cidade do Recife, por ocasião da outorga do título de Cidadão Pernambucano. 
Algumas dessas ilhas ocupam espaços aglutinadores, constituindo polos regionais. Em torno delas gravitam naturalmente ilhas conexas. Esse é o caso de Pernambuco. Historicamente reconhecido como núcleo regional, ponto de convergência dos componentes insulares do Nordeste.

Em passado remoto, Pernambuco ocupou o tríplice papel de vetor econômico, político e cultural da região. Na atualidade, continua a ser reconhecido como sua vanguarda cultural. Não se trata de mera figura de retórica, mas de realidade palpável. Que pode ser diagnosticada através do exame da trajetória da intelectualidade alagoana, paraibana, potiguar, cearense, piauiense e sergipana. Em menor grau, figuram os baianos e os maranhenses, situados em lugares fronteiriços. Oscilam entre a atração pernambucana e as seduções metropolitanas do Sudeste ou do Norte. Ou então acumulam capital para se tornar polos autônomos.

Esse poder de atração, sedução e encantamento que ostenta Pernambuco decorre da construção e da reprodução de sua identidade cultural. Como se configura essa identidade?

Ela transparece a atitude bem humorada, popularmente difundida em tempos de paz ou de guerra.

No tempo da guerra, era exemplificada através da vinheta que iniciava a programação 
de sua emissora-líder: - Rádio Jornal do Comércio, Pernambuco falando diretamente para o mundo.

Nos tempos de paz, ela se traduz pelo culto ao jornal mais antigo em circulação na América Latina, contida na exclamação: Só acredito que o mundo acabou quando a notícia sair na primeira página do Diário de Pernambuco!

Mas, sem dúvida alguma, a marca retumbante de sua identidade cívica, catalisada pelo Hino Estadual: "Pernambuco, imortal, imortal" - persiste naqueles signos nacionalmente reconhecidos e regionalmente aclamaados.

Por exemplo: o heroísmo republicano de Frei Caneca, o abolicionismo diplomático de Joaquim Nabuco e o civismo nacionalista de Barbosa Lima Sobrinho.

Mas também: a geografia da fome de Josué de Castro, a pedagogia do oprimido de Paulo Freire e a sociologia do cotidiano de Gilberto Freyre.

Ou então: a poesia de Manuel Bandeira ou de João Cabral de Melo Neto, a pintura de Vicente do Rego Monteiro e de Jaime Câmara, a escultura de Francisco Brennand e de Abelardo da Hora. Ela ainda pode se destacar: no frevo de Capiba, no baião de Luiz Gonzaga, na cerâmica de Vitalino. 
Em última instância, figura inevitavelmente nas iguarias do patrimônio coletivo, como a tapioca, o bolo de rolo, o sarapatel, a cartola e o licor de pitanga.

Identificado com esse simbolismo, sinto-me contente e orgulhoso ao receber o título de Cidadão Pernambucano. Na verdade, acolho essa distinção que me confere a Assembleia Legislativa do Estado como se fora a continuidade, melhor dizendo, a consolidação, daqueles laços afetivos que cultivei na infância e na mocidade.

Quando criança, visitei periodicamente a cidade de Águas Belas, primitiva aldeia dos 30 fulni-ô, tribo indígena que outrora habitou também o espaço em que me criei - a comunidade alagoana limítrofe, Santana do Ipanema. O motivo das minhas visitas, naturalmente monitorado por familiares adultos, era a de rever parentes que ali fincaram raízes. Mas o que permaneceu viva na minha memória foi a lembrança dos torés, ritual cultivado pela diáspora fulni-ô. Espalhada por todo o sertão circunvizinho de Pernambuco, Alagoas e Bahia, seus encontros anuais, à sombra dos juazeiros, eram regados a jurema, bebida que provoca efeitos alucinógenos.

Ao chegar à maioridade, na época dos estudos universitários, vivi nesta cidade do Recife. Aqui me formei e comecei a carreira 
acadêmica, na área de jornalismo. Aqui me casei e constitui família, assimilando os hábitos e costumes da terra. Aqui enveredei pela política, solidário com a utopia acalentada pelos contingentes que alçaram Miguel Arraes à liderança do governo pernambucano. Aqui também curti minhas desilusões políticas, tomando a firme decisão de optar exclusivamente pela vida universitária.

O golpe de 1964 conduziu-me ao exílio dentro do próprio país, impulsionando minha vocação de andarilho mundial. Em São Paulo, convivi intensamente com a diáspora pernambucana.

Hoje, no ocaso da vida acadêmica, sinto-me revigorado por tão significativa homenagem. Ouso engrossar a fileira daqueles pernambucanos nativos que lançaram as bases de uma corrente cuja marca registrada tem sido o resgate da identidade pernambucana.

Constituindo patrimônio cognitivo destinado às futuras gerações, tais pesquisas estão embasadas naquele acervo construído por Pereira da Costa e por Oliveira Lima.

Pereira da Costa legou, no final do século XIX, a "coluna vertebral" do ethos pernambucano. Trata-se dos Anais Pernambucanos, obra em 10 volumes, contendo um repertório exaustivo de pessoas e instituições que deram sentido à sua cultura. . 
Oliveira Lima garimpou os "fatos pernambucanos" que Ihe pareceram relevantes no inventário de Pereira da Costa, com a intenção de relacioná-los com a "marcha da civilização brasileira", confrontado-os também com os "acontecimentos do Velho Mundo".

Mas o verdadeiro fundador desse território conhecido como Estudos Pernambucanos é Alfredo de Carvalho, autor da primeira obra assim denominada. Dedicada ao desbravador Pereira da Costa e saudada por Oliveira Lima como nossa petite histoire, essa obra, publicada em 1907, rompe os cânones da exaltação aos grandes feitos históricos, privilegiando episódios marcantes da vida cotidiana. Seu foco está concentrado na paisagem, na pré-história, nos motins políticos e no jornalismo literário, destacando a presença forânea, no espaço pernambucano: as invasões batavas, as ideias de Racine e a lírica de Castro Alves ou os relatos de viajantes como Waterton e Swainson.

Meio século depois, apareceria o segundo livro rotulado como Estudos Pernambucanos. Datado de 1956, reúne dez ensaios escritos pelo jornalista Aníbal Fernandes, previamente lidos em conferências que ministrou em várias cidades brasileiras.

Passado outro quarto de século, Barbosa Lima Sobrinho lançou o livro Assuntos Pernambucanos (1986), também, formado 
por ensaios sobre temas diversos, abrangendo desde a guerra dos mascates ao povoamento do sertão do São Francisco, passando pela revolução praieira e destacando o protagonismo de paradigmas pernambucanos, entre eles Nabuco, Freyre, Carneiro Leão e o herói bolivariano Abreu e Lima.

Essa trilogia constitui o que chamo de "antigos" estudos, a ela ousando acrescentar uma coletânea de minha autoria, organizada e editada por Maria Cristina Gobbi, recentemente lançada no Festival Literário do Vale do São Francisco, com o modesto título Novos Estudos Pernambucanos, mas ostentando ambicioso subtítulo Pernambuco na Idade Mídia.

Trata-se de um gesto de reconhecimento do neófito cidadão pernambucano, que sem renunciar às suas raízes caetés, sente-se gratificado pela decisão da Assembleia Legislativa, incluindo-o na galeria dos pernambucanos honorários. Se já me orgulhava de pertencer ao seleto clube dos Cidadãos Recifenses, a partir de hoje, posso me rejubilar como Cidadão Pernambucano, de fato e de direito.

Agora faço parte daquela plêiade de intelectuais alagoanos que assumiram voluntária e conscientemente o ethos da pernambucanidade. Destacando os conterrâneos ilustres - Tadeu Rocha, Arnoldo Jambo e Carlos Cavalcante - cujas carreiras foram construídas 
no Diário de Pernambuco, quero homenageálos como modelos de jornalistas nos quais podemos buscar inspiração, alento, perseverança.

Mas não posso deixar de fazer referência a duas figuras historicamente vinculadas ao legislativo pernambucano, com as quais convivi durante o tempo em que aqui atuei nos idos de 60. Um deles, o jornalista Luiz Beltrão, servidor da casa, que a ela prestou relevantes serviços jornalísticos e que me ensinou o ofício noticioso. O outro, um combativo deputado, cuja biografia honra Pernambuco pela coragem, retidão e heroísmo - David Capistrano - com que me deu lições de civismo.

34 Com grande emoção, pleno reconhecimento e muita humildade, a eles dedico o galardão que recebo neste momento. 